\title{
Nicotine modulates the long-lasting storage of fear memory
}

\author{
Ramón H. Lima, ${ }^{1,2,3}$ Andressa Radiske, ${ }^{1,2,3}$ Cristiano A. Köhler, ${ }^{1,2}$ Maria \\ Carolina Gonzalez, ${ }^{1,2}$ Lia R. Bevilaqua, ${ }^{1,2}$ Janine I. Rossato, ${ }^{1,2}$ Jorge H. Medina, ${ }^{1,2}$ \\ and Martín Cammarota ${ }^{1,2,4}$
}

${ }^{1}$ Laboratory of Behavioral Neurobiology, Biomedical Research Institute, Pontifical Catholic University of Rio Grande do Sul (PUCRS), Porto Alegre 90610-000, Brazil; ${ }^{2}$ Memory Laboratory, Department of Physiology, School of Medicine, University of Buenos Aires (UBA), Buenos Aires CP1 121, Argentina

\begin{abstract}
Late post-training activation of the ventral tegmental area (VTA)-hippocampus dopaminergic loop controls the entry of information into long-term memory (LTM). Nicotinic acetylcholine receptors ( $\mathrm{nAChR}$ ) modulate VTA function, but their involvement in LTM storage is unknown. Using pharmacological and behavioral tools, we found that $\alpha 7$-nAChR-mediated cholinergic interactions between the pedunculopontine tegmental nucleus and the medial prefrontal cortex modulate the duration of fear-motivated memories, maybe by regulating the activation state of VTA-hippocampus dopamine connections.
\end{abstract}

Evidence suggests that nicotinic acetylcholine receptor (nAChR) agonists ameliorate the cognitive decline associated with schizophrenia and Alzheimer's disease (AD) progression (Barrantes et al. 2010; AhnAllen et al. 2012). Long-term memory (LTM) storage requires activation of the ventral tegmental area (VTA)-hippocampus dopaminergic loop (Lisman and Grace 2005) and synthesis of brain-derived neurotrophic factor (BDNF; Bekinschtein et al. 2007). Indeed, we have previously shown that the VTA-hippocampus loop is specifically active late after learning and, through a process involving the D1/D5 dopamine receptordependent increase of BDNF expression in the CA1 region of the dorsal hippocampus, determines LTM duration (Rossato et al. 2009). Therefore, since nicotine modulates VTA function (Wooltorton et al. 2003) and cholinergic inputs to the VTA have excitatory influence on mesolimbic dopamine neurons (Good and Lupica 2009; Yang et al. 2009; Zhao-Shea et al. 2011), contributing to signal behaviorally relevant events as well as the rewarding properties of stimuli (Mansvelder et al. 2003; Chen et al. 2006; Ikemoto 2007; Besson et al. 2012), we investigated the involvement of nAChRs on fear memory persistence. To that end, we utilized the step-down inhibitory avoidance (IA) learning task and 3-mo-old male Wistar rats. Animals were maintained under a 12 -h light/dark cycle at $22^{\circ} \mathrm{C}$ with ad libitum access to food and water. One week before training, rats were bilaterally implanted under deep anesthesia with 22-gauge guides aimed to the CA1 region of the dorsal hippocampus, the VTA, the medial prefrontal cortex (mPFC), the pedunculopontine tegmental nucleus (PPTg), and/or the laterodorsal tegmental nucleus (LDTg) in accordance with coordinates taken from the atlas of Paxinos and Watson 1986 (CA1: AP - 4.2/LL $\pm 3.0 / \mathrm{DV}-3.0$; VTA: AP $-4.8 / \mathrm{LL} \pm 1.0 /$ DV -9.0; mPFC: AP +3.2/LL $\pm 0.8 / \mathrm{DV}-4.0$; PPTg: AP $-8.0 / \mathrm{LL}$ $\pm 2.0 / \mathrm{DV}-8.0$; LDTg: AP $-9.1 / \mathrm{LL} \pm 0.7 / \mathrm{DV}-8.0)$. IA training was carried out in a $50-\mathrm{cm} \times 25-\mathrm{cm} \times 25-\mathrm{cm}$ Plexiglas box with a

\footnotetext{
${ }^{3}$ These authors contributed equally to this work.

${ }^{4}$ Corresponding author

E-mail mcammaro@terra.com.br

Article is online at http://www.learnmem.org/cgi/doi/10.1101//m.029900.112.
}

5-cm-high, 8-cm-wide, and 25-cm-long wood platform on the left end of a series of bronze bars making the floor of the box. During training, the animals were placed on the platform facing the left rear corner of the box. When they stepped down to the grid, they received a $0.4 \mathrm{~mA}$ (weak training) or a $0.8 \mathrm{~mA}$ (strong training) scrambled footshock during $2 \mathrm{sec}$ and were immediately withdrawn from the training box. LTM was assessed $2 \mathrm{~d}$ or $14 \mathrm{~d}$ later. Latency to step down during the test session was taken as an indicator of retention. Placement of the cannulas was verified postmortem. Only data from rats with correct implants were included in the statistical analyses. All efforts were made to reduce the number of animals used and to minimize their suffering. Experimental procedures followed the guidelines set by the US National Institutes of Health.

When IA training was performed using a weak footshock as reinforcer, it generated a LTM that decayed rapidly, lasting no more than $2 \mathrm{~d}$. On the contrary, IA training with a strong footshock induced a long-lasting LTM persisting $14 \mathrm{~d}$ or longer (Fig. $1 \mathrm{~A} ; t_{(15)}=4.083, P<0.01$ for $2 \mathrm{~d}$ post-training; $t_{(12)}=5.170, P<$ 0.001 for $14 \mathrm{~d}$ post-training). Bilateral intra-VTA infusion of nicotine (NIC) $12 \mathrm{~h}$ after weak IA training facilitated retention $14 \mathrm{~d}$ but not $2 \mathrm{~d}$ post-training (Fig. $1 \mathrm{~B} ; F_{(3,53)}=0.162, P=0.92$ for $2 \mathrm{~d}$ posttraining and $F_{(3,58)}=6.545, P<0.001$ for $14 \mathrm{~d}$ post-training; $q=$ 4.359, $P<0.001$ for $6-\mu \mathrm{g} /$ side NIC vs. VEH in Dunnet's test after ANOVA). Conversely, intra-VTA administration of the nonsubtype specific nAChR antagonist mecamylamine (MEC) (Fig. 1C; $F_{(3,40)}=3.791, P<0.05 ; q=2.511, P<0.05$ for $5 \mu \mathrm{g} /$ side and $q=3.162, P<0.01$ for $10 \mu \mathrm{g} /$ side vs. VEH in Dunnet's test after ANOVA), or of the $\alpha 7$-nAChR antagonist methyllycaconitine (MLA) (Fig. $1 \mathrm{D} ; F_{(2,27)}=9.717, P<0.001 ; q=3.273, P<0.01$ vs. VEH in Dunnet's test after ANOVA) $12 \mathrm{~h}$ after strong IA training impaired LTM $14 \mathrm{~d}$ later. The $\alpha 4 / \beta 2$-nAChR antagonist dihydro$\beta$-erythroidine (DH $\beta \mathrm{E}$ ) had no effect on memory when given in VTA $12 \mathrm{~h}$ post-training (Fig. $1 \mathrm{D} ; q=0.921, P>0.05$ vs. VEH in Dunnet's test after ANOVA).

Earlier, we demonstrated that late post-training activation of hippocampal D1/D5 receptors controls BDNF signaling to promote the lasting storage of the mnemonic trace (Rossato et al. 
A

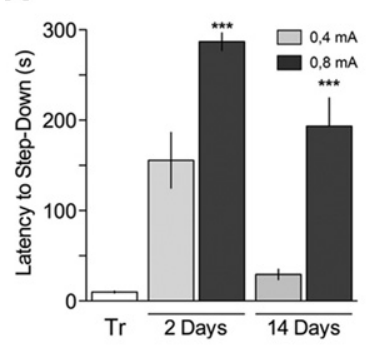

C

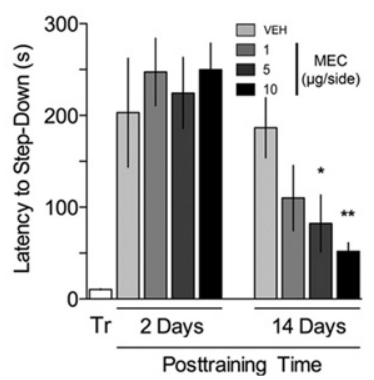

B

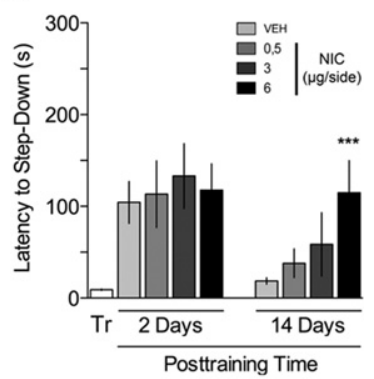

D

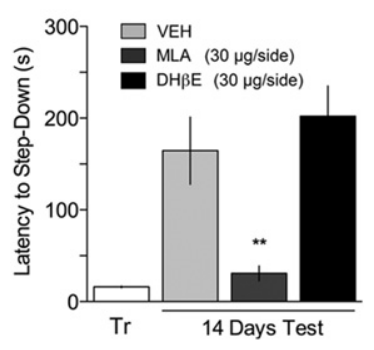

Figure 1. Activation of VTA $\alpha 7-n A C h R$ late after training modulates long-term memory persistence. $(A)$ Animals were trained in IA using a weak $(0.4 \mathrm{~mA} / 2 \mathrm{sec})$ or a strong $(0.8 \mathrm{~mA} / 2 \mathrm{sec})$ footshock and long-term memory retention was assessed either $2 \mathrm{~d}$ or $14 \mathrm{~d}$ later. (B) Animals were trained in IA using a weak footshock and $12 \mathrm{~h}$ later received bilateral intra-VTA infusions of vehicle (VEH; $0.1 \%$ DMSO in saline) or nicotine (NIC). Retention was evaluated $2 \mathrm{~d}$ or $14 \mathrm{~d}$ later. (C) Animals were trained in IA using a strong footshock and $12 \mathrm{~h}$ later received bilateral intra-VTA infusions of VEH or mecamylamine (MEC). Retention was evaluated $2 \mathrm{~d}$ or $14 \mathrm{~d}$ later. $(D)$ Animals trained in IA using a strong footshock received bilateral intra-VTA infusions of VEH, methyllycaconitine (MLA), or dihydro- $\beta$-erythroidine $(\mathrm{DH} \beta \mathrm{E}) 12 \mathrm{~h}$ post-training. Long-term memory was assessed $14 \mathrm{~d}$ thereafter. Data are presented as mean $\pm \mathrm{SEM} ; n=$ 8-10 per group. (***) $P<0.001$, (**) $P<0.01$, and $\left(^{*}\right) P<0.05$ in Dunnet's test after ANOVA.

2009). Here, we found that bilateral intra-CA1 infusion of the dopamine D1/D5 receptor antagonist SCH23390 (SCH) blocked the promnesic effect of intra-VTA NIC (Fig. $2 \mathrm{~A} ; F_{(2,33)}=14.210, P<$ $0.001 ; q=4.827, P<0.001$ for NIC vs. VEH and $q=0.248, P>$ 0.05 for NIC $+\mathrm{SCH}$ vs. VEH in Dunnet's test after ANOVA). On the contrary, intra-CA1 administration of the dopamine D1/D5 receptor agonist SKF38393 (SKF) reversed the amnesia caused by intra-VTA MEC (Fig. 2B; $F_{(2,15)}=5.641, P<0.05 ; q=2.530, P<$ 0.05 for MEC vs. VEH and $q=0.668$ for MEC + SKF vs. VEH in Dunnet's test after ANOVA).

Cholinergic projections to the VTA derive mainly from PPTg (Sugimoto and Hattori 1984; Hallanger and Wainer 1988; Oakman et al. 1995, Geisler and Zahm 2005). PPTg activation increases dopamine neurons firing (Klitenick and Kalivas 1994; Floresco et al. 2003), and it has been suggested that this nucleus controls goal-directed behavior by integrating sensory and limbic inputs to modulate the motivational, rewarding, and noveltydetection functions of the VTA (Olmstead et al. 1998). Indeed, it was proposed that PPTg neurons could relay the excitatory components of both expected and actual reward signals to VTA dopamine neurons (Laviolette et al. 2002; Pidoplichko et al. 2004; Kobayashi and Okada 2007; Okada et al. 2009). In that respect, it is known that reversible inactivation of the PPTg suppresses conditioned sensory responses of dopamine neurons in rats (Pan and Hyland 2005), and that PPTg lesions hinder the acquisition of associations between rewards and neutral stimuli (Inglis et al. 2000)

as well as conditioned-place preference to drugs of abuse (Bechara and van der Kooy 1989; Olmstead and Franklin 1993). Nicotine application, paired with postsynaptic stimulation, contributes to the induction of long-term potentiation (LTP) of VTA dopamine neurons, an effect attributed to presynaptic $\alpha 7-n A C h R s$ on glutamatergic afferents, and it has been speculated that such cholinergic mechanisms could be associated with modifications in synaptic strength subserving learning and memory (Mansvelder and McGehee 2000; Fagen et al. 2003; Jones and Wonnacott 2004). We found that reversible inactivation of the PPTg $12 \mathrm{~h}$ after strong training, but not of the LDTg which also sends cholinergic projections to VTA (Oakman et al. 1995), impaired LTM persistence. Intra-VTA infusion of NIC or intra-CA1 infusion of SKF reversed the amnesia induced by PPTg inactivation (Fig. 3A; $F_{(3,33)}=$ 8.310, $P<0.001 ; q=3.181, P<0.01$ for muscimol [MUS] vs. VEH; $q=0.951, P>0.05$ for MUS + SKF vs. VEH; $q=0.566, P>$ 0.05 for MUS + NIC vs. VEH in Dunnet's test after ANOVA. Fig. $\left.3 \mathrm{~B} ; t_{(17)}=0.636, P=0.53\right)$. Likewise, temporary inactivation of the MPFC hindered LTM persistence, and this effect was reversed by infusion of NIC or N-methyl-D-aspartate (NMDA) in VTA (Fig. $3 \mathrm{C} ; F_{(3,41)}=5.259, P<0.01 ; q=2.530, P<0.05$ for MUS vs. VEH; $q=1.444, P>0.05$ for MUS + NIC vs. VEH; $q=0.008, P>0.05$ for MUS + NMDA vs. VEH in Dunnet's test after ANOVA), as well as by SKF and recombinant BDNF microinjected in dorsal CA1 $12 \mathrm{~h}$ post-training (Fig. 3D; $F_{(3,42)}=3.882, P<0.05 ; q=$ 3.133, $P<0.01$ for MUS vs. VEH; $q=0.480, P>0.05$ for MUS + SKF vs. VEH; $q=0.620, P>0.05$ for MUS + BDNF vs. VEH in Dunnet's test after ANOVA). Pharmacological activation of PPTg NMDA receptors increases burst firing of VTA dopamine neurons (Lodge and Grace 2006a), and recently it has been proposed that $\alpha 7-n A C h R$ activation in VTA-containing brain slices enhances glutamatergic synaptic strength on dopamine neurons by modulating glutamate presynaptic release (Jin et al. 2011). We found that, when given in PPTg $12 \mathrm{~h}$ after weak training, NMDA facilitated LTM retention $14 \mathrm{~d}$ later (Fig. $3 \mathrm{E} ; F_{(2,27)}=15.220, P<0.001$; $q=4.885, P<0.001$ vs. VEH in Dunnet's test after ANOVA). However, this promnesic effect was totally blocked by co-infusion of muscimol in mPFC (Fig. 3E; $q=0.221, P>0.05$ vs. VEH in Dunnet's test after ANOVA), further endorsing the idea that a fully functional $\mathrm{mPFC}$ is necessary late after training for enduring consolidation of IA memory, and indicating that this cortex is
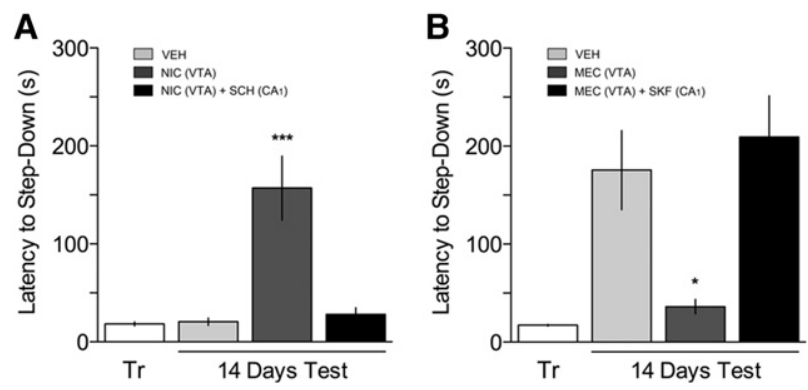

Figure 2. The modulatory effect of VTA $\alpha 7-n A C h R$ on long-term memory persistence depends on the activation state of hippocampal dopamine D1/D5 receptors. Animals were trained in the IA task using a weak $(A)$ or a strong $(B)$ 2-s footshock as unconditioned stimulus, and long-term memory was assessed $14 \mathrm{~d}$ later. $(A)$ Twelve hours after training, animals received bilateral infusions of either vehicle (VEH; $0.1 \%$ DMSO in saline) in both VTA and dorsal CA1, or nicotine (NIC; 6- $\mu \mathrm{g} / \mathrm{side}$ ) in VTA plus VEH in dorsal CA1, or NIC in VTA plus SCH23390 (SCH; $1.5-\mu \mathrm{g} / \mathrm{side})$ in dorsal CA1. (B) Twelve hours after training, animals received bilateral infusions of either vehicle (VEH; $0.1 \%$ DMSO in saline) in both VTA and dorsal CA1, or mecamylamine (MEC; $10 \mu \mathrm{g} /$ side) in VTA plus VEH in dorsal CA1, or MEC in VTA plus SKF38393 (SKF; $12.5 \mu \mathrm{g} /$ side) in dorsal CA1. Data are presented as mean \pm SEM; $n=8-10$ per group. 
A

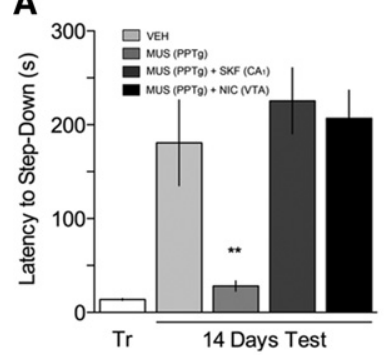

C

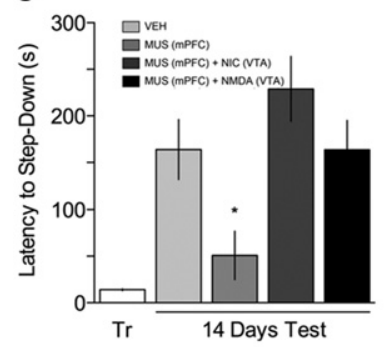

B

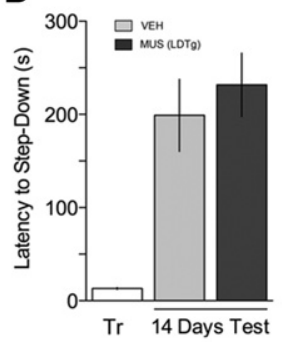

D

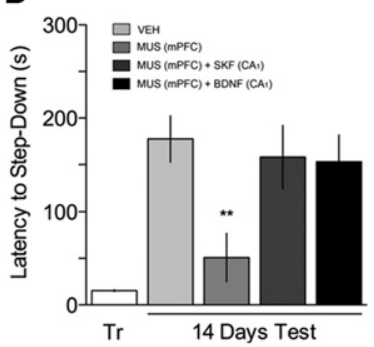

E

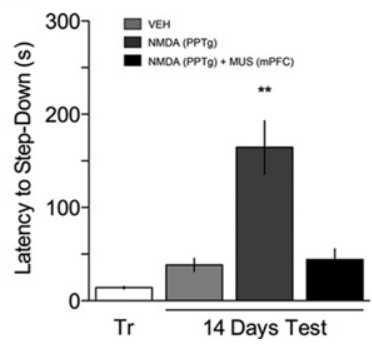

Figure 3. Late post-training inactivation of PPTg or MPFC hinders LTM persistence and this effect is reversed by stimulation of the VTA-hippocampal loop and by intra-CA1 administration of BDNF. Animals were trained in the IA task using a strong $(A-D ; 0.8 \mathrm{~mA} / 2 \mathrm{sec})$ or a weak $(E ;$ $0.4 \mathrm{~mA} / 2 \mathrm{sec}$ ) footshock, and LTM was assessed $14 \mathrm{~d}$ later. $(A)$ Twelve hours after training, animals received bilateral infusions of either vehicle (VEH; $0.1 \%$ DMSO in saline) in both PPTg and dorsal CA1, or muscimol (MUS; $0.5 \mu \mathrm{g} / \mathrm{side}$ ) in PPTg plus VEH in dorsal CA1, or MUS in PPTg plus SKF38393 (SKF; $12.5 \mu \mathrm{g} / \mathrm{side}$ ) in dorsal CA1, or MUS in PPTg plus nicotine (NIC; $6 \mu \mathrm{g} /$ side) in VTA. (B) Twelve hours after training, animals received bilateral infusions of either vehicle (VEH; $0.1 \%$ DMSO in saline) or muscimol (MUS; $0.5 \mu \mathrm{g} /$ side) in LDTg. (C) Twelve hours after training, animals received bilateral infusions of either vehicle (VEH; $0.1 \%$ DMSO in saline) in both MPFC and VTA, or muscimol (MUS; 0.5 $\mu \mathrm{g} /$ side) in mPFC plus VEH in dorsal VTA, MUS in MPFC plus NIC in dorsal VTA, or MUS in mPFC plus NMDA $(0.2 \mu \mathrm{g} / \mathrm{side})$ in VTA. (D) Twelve hours after training, animals received bilateral infusions of either vehicle (VEH; $0.1 \%$ DMSO in saline) in both $\mathrm{mPFC}$ and dorsal CA1, or muscimol (MUS; $0.5 \mu \mathrm{g} / \mathrm{side}$ ) in mPFC plus VEH in dorsal CA1, MUS in mPFC plus SKF in dorsal CA1, or MUS in mPFC plus BDNF $(0.25 \mu \mathrm{g} /$ side) in dorsal CA1. (E) Twelve hours after training, animals received bilateral infusions of either vehicle (VEH; $0.1 \%$ DMSO in saline) in both PPTg and $\mathrm{mPFC}$, or NMDA $(0.2 \mu \mathrm{g} / \mathrm{side})$ in PPTg plus VEH in MPFC, or NMDA in PPTg plus muscimol (MUS; $0.5 \mu \mathrm{g} / \mathrm{side}$ ) in $\mathrm{mPFC}$. Data are presented as mean \pm SEM; $n=8-10$ per group.

essential to elicit the promnesic effect induced by pharmacological stimulation of the cholinergic system. Taken together, our results suggest that PPTg/mPFC interactions, probably mediated by $\alpha 7-n A C h R$, would control the activation state of the VTA-hippocampus dopaminergic loop to modulate the persistent storage of fear memories (Fig. 4). Alternatively, the PPTg-mPFC circuit could be operating in parallel and not in series with the VTA-hip-

pocampus loop during late memory processing and therefore pharmacological activation of VTA would be merely compensating for inactivation of PPTg and/or mPFC. However, since (1) our experiments indicate that PPTg needs a functioning $\mathrm{mPFC}$ to modulate memory persistence, (2) the amnesia induced by PPTg inactivation was reversed by pharmacological activation of VTA, (3) we have previously demonstrated that the amnesic effect of VTA inactivation is reversed only by the pharmacological activation of hippocampal D1/D5 receptors, and (4) to the best of our knowledge there are no direct dopaminergic projections from either mPFC or PPTg to the hippocampus but, instead, burst-like activation of mPFC massively increases dopamine neuron firing in VTA (Lodge 2011), we believe such a mechanism, although it is not completely implausible, is also unlikely to account for our results. Compensatory effects on VTA function mediated by mPFC/ accumbens/VTA feedback connections (Rahman and McBride 2002; McFarland et al. 2004; Schmidt et al. 2009) are also unlikely to account for our results since pharmacological modulation of the nucleus accumbens $12 \mathrm{~h}$ after training does not affect IA LTM persistence. No less importantly, our finding that late posttraining inactivation of PPTg, but not of LDTg, impairs memory storage is consistent with the idea that cholinergic afferents from PPTg directly regulate firing of DA neurons in the VTA (Lokwan et al. 1999; Floresco et al. 2003), and suggest that participation of this system in LTM persistent storage does not involve a LDTg-mediated shift from single-spike (i.e., tonic) to burst-firing (i.e., phasic) mode, a change in the firing pattern of dopamine

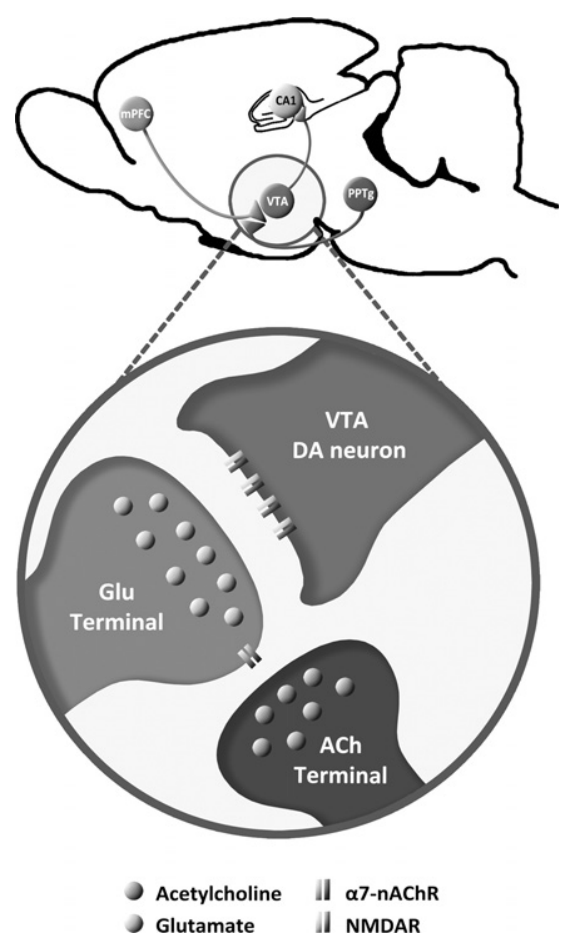

Figure 4. Diagram showing the putative events mediating the involvement of $\alpha 7$-nAChR in the persistent storage of long-lasting memory. ACh released late after training in the VTA from PPTg efferents (Klitenick and Kalivas 1994; Floresco et al. 2003; Chen et al. 2006) activates $\alpha 7$-nAChR located on the axon terminals of mPFC glutamatergic neurons, thus increasing glutamate release and potentiating excitatory inputs to VTA dopamine neurons (Mansvelder and McGehee 2000; Good and Lupica 2009). This potentiation would increase dopamine release in CA1 and, hence, the activation state of dopamine D1/D5 receptors in this region, which in turn induces the synthesis of hippocampal BDNF necessary and sufficient for memory storage. 
VTA neurons that has been earlier associated with the acquisition of new information, albeit not with memory storage (Schultz 1998; Lodge and Grace 2006b; Grace et al. 2007). In this regard, while this paper was under revision it was demonstrated that inputs to VTA from LDTg preferentially synapse on dopamine neurons projecting to the nucleus accumbens and elicit appetitive but not aversive memories (Lammel et al. 2012).

In conclusion, our data add to previous findings suggesting that the VTA-hippocampus dopaminergic loop is a final common pathway for both top-down and bottom-up influences on late memory processing and indicates, as proposed formerly, that modulation of $\alpha 7-n A C h R$ may represent an important target for treatment of the increased forgetting observed in normal aging, mild cognitive impairment, and $\mathrm{AD}$ patients (Woodruff-Pak et al. 2010; Kawamata and Shimohama 2011; Wallace and Porter 2011).

\section{Acknowledgments}

This study was supported by grants from Conselho Nacional de Desenvolvimento Científico e Tecnológico (CNPq, Brazil), Fundação de Amparo à Pesquisa do Estado do Rio Grande do Sul (FAPERGS, Brazil), and Coordenação de Aperfeiçoamento de Pessoal de Nível Superior (CAPES, Brazil) to M.C.; Consejo Nacional de Investigaciones Ciéntificas y Tecnológicas (CONICET, Argentine) to J.H.M.; and International Brain Research Organization (IBRO) to M.C. and J.H.M. R.H.L. and A.R. are recipients of PhD fellowships from Programa de Pós-Graduação em Gerontologia Biomédica (PUCRS, Brazil) and C.A.K. is a Post-doctoral Research Fellow supported by CNPq, all supervised by M.C. M.C.G. is a CONICET PhD student supervised by J.H.M.

\section{References}

AhnAllen CG. 2012. The role of the $\alpha 7$ nicotinic receptor in cognitive processing of persons with schizophrenia. Curr Opin Psychiatry 25: $103-108$.

Barrantes FJ, Borroni V, Vallés S. 2010. Neuronal nicotinic acetylcholine receptor-cholesterol crosstalk in Alzheimer's disease. FEBS Lett 3: 1856-1863.

Bechara A, van der Kooy D. 1989. The tegmental pedunculopontine nucleus: A brain-stem output of the limbic system critical for the conditioned place preferences produced by morphine and amphetamine. J Neurosci 9: 3400-3409.

Bekinschtein P, Cammarota M, Igaz LM, Bevilaqua LR, Izquierdo I, Medina JH. 2007. Persistence of long-term memory storage requires a late protein synthesis- and BDNF-dependent phase in the hippocampus. Neuron 53: 261-277.

Besson M, David V, Baudonnat M, Cazala P, Guilloux JP, Reperant C, Cloez-Tayarani I, Changeux JP, Gardier AM, Granon S. 2012. 7-nicotinic receptors modulate nicotine-induced reinforcement and extracellular dopamine outflow in the mesolimbic system in mice. Psychopharmacology 220: $1-14$.

Chen J, Nakamura M, Kawamura T, Takahashi T, Nakahara D. 2006. Roles of pedunculopontine tegmental cholinergic receptors in brain stimulation reward in the rat. Psychopharmacology 184: 514-522.

Fagen ZM, Mansvelder HD, Keath JR, McGehee DS. 2003. Short- and long-term modulation of synaptic inputs to brain reward areas by nicotine. Ann N Y Acad Sci 1003: 185-195.

Floresco SB, West AR, Ash B, Moore H, Grace AA. 2003. Afferent modulation of dopamine neuron firing differentially regulates tonic and phasic dopamine transmission. Nat Neurosci 6: 968-973.

Geisler S, Zahm DS. 2005. Afferents of the ventral tegmental area in the rat-anatomical substratum for integrative functions. J Comp Neurol 490: $270-294$

Good CH, Lupica CR. 2009. Properties of distinct ventral tegmental area synapses activated via pedunculopontine or ventral tegmental area stimulation in vitro. J Physiol 587: 1233-1247.

Grace AA, Floresco SB, Goto Y, Lodge DJ. 2007. Regulation of firing of dopaminergic neurons and control of goal-directed behaviors. Trends Neurosci 30: 220-227.

Hallanger AE, Wainer BH. 1988. Ascending projections from the pedunculopontine tegmental nucleus and the adjacent mesopontine tegmentum in the rat. J Comp Neurol 274: 483-515.
Ikemoto S. 2007. Dopamine reward circuitry: Two projection systems from the ventral midbrain to the nucleus accumbens-olfactory tubercle complex. Brain Res Rev 56: 27-78.

Inglis WL, Olmstead MC, Robbins TW. 2000. Pedunculopontine tegmental nucleus lesions impair stimulus-reward learning in autoshaping and conditioned reinforcement paradigms. Behav Neurosci 114: $285-294$.

Jin Y, Yang K, Wang H, Wu J. 2011. Exposure of nicotine to ventral tegmental area slices induces glutamatergic synaptic plasticity on dopamine neurons. Synapse 65: 332-338.

Jones IW, Wonnacott S. 2004. Precise localization of $\alpha 7$ nicotinic acetylcholine receptors on glutamatergic axon terminals in the rat ventral tegmental area. J Neurosci 24: 11244-11252.

Kawamata J, Shimohama S. 2011. Stimulating nicotinic receptors trigger multiple pathways attenuating cytotoxicity in models of Alzheimer's and Parkinson's diseases. J Alzheimers Dis 24: 95-109.

Klitenick MA, Kalivas PW. 1994. Behavioral and neurochemical studies of opioid effects in the pedunculopontine nucleus and mediodorsal thalamus. J Pharmacol Exp Ther 269: 437-448.

Kobayashi Y, Okada K. 2007. Reward prediction error computation in the pedunculopontine tegmental nucleus neurons. Ann N Y Acad Sci 1104: 310-323.

Lammel S, Lim BK, Ran C, Huang KW, Betley MJ, Tye KM, Deisseroth K, Malenka RC. 2012. Input-specific control of reward and aversion in the ventral tegmental area. Nature 419: 212-217.

Laviolette SR, Alexson TO, van der Kooy D. 2002. Lesions of the tegmental pedunculopontine nucleus block the rewarding effects and reveal the aversive effects of nicotine in the ventral tegmental area. J Neurosci 22: $8653-8660$.

Lisman JE, Grace AA. 2005. The hippocampal-VTA loop: Controlling the entry of information into long-term memory. Neuron 46: 703-713.

Lodge DJ. 2011. The medial prefrontal and orbitofrontal cortices differentially regulate dopamine system function. Neuropsychopharmacology 36: 1227-1236.

Lodge DJ, Grace AA. 2006a. The laterodorsal tegmentum is essential for burst firing of ventral tegmental area dopamine neurons. Proc Natl Acad Sci 103: 5167-5172.

Lodge DJ, Grace AA. 2006b. The hippocampus modulates dopamine neuron responsivity by regulating the intensity of phasic neuron activation. Neuropsychopharmacology 31: 1356-1361.

Lokwan SJ, Overton PG, Berry MS, Clark D. 1999. Stimulation of the pedunculopontine tegmental nucleus in the rat produces burst firing in A9 dopaminergic neurons. Neuroscience 92: 245-254.

Mansvelder HD, McGehee DS. 2000. Long-term potentiation of excitatory inputs to brain reward areas by nicotine. Neuron 27: 349-357.

Mansvelder HD, De Rover M, McGehee DS, Brussaard AB. 2003. Cholinergic modulation of dopaminergic reward areas: Upstream and downstream targets of nicotine addiction. Eur J Pharmacol 480: $117-123$.

McFarland K, Davidge SB, Lapish CC, Kalivas PW. 2004. Limbic and motor circuitry underlying footshock-induced reinstatement of cocaine-seeking behavior. J Neurosci 24: 1551-1560.

Oakman SA, Faris PL, Kerr PE, Cozzari C, Hartman BK. 1995. Distribution of pontomesencephalic cholinergic neurons projecting to substantia nigra differs significantly from those projecting to ventral tegmental area. J Neurosci 15: 5859-5869.

Okada K, Toyama K, Inoue Y, Isa T, Kobayashi Y. 2009. Different pedunculopontine tegmental neurons signal predicted and actual task rewards. J Neurosci 29: 4858-4870.

Olmstead MC, Franklin KB. 1993. Effects of pedunculopontine tegmental nucleus lesions on morphine-induced conditioned place preference and analgesia in the formalin test. Neuroscience 57: $411-418$.

Olmstead MC, Munn EM, Franklin KB, Wise RA. 1998. Effects of pedunculopontine tegmental nucleus lesions on responding for intravenous heroin under different schedules of reinforcement. J Neurosci 18: 5035-5044.

Pan WX, Hyland BI. 2005. Pedunculopontine tegmental nucleus controls conditioned responses of midbrain dopamine neurons in behaving rats. J Neurosci 25: $4725-4732$.

Paxinos G, Watson C. 1986. The rat brain in stereotaxic coordinates. Academic Press, New York.

Pidoplichko VI, Noguchi J, Areola OO. 2004. Nicotinic cholinergic synaptic mechanisms in the ventral tegmental area contribute to nicotine addiction. Learn Mem 11: 60-69.

Rahman S, McBride WJ. 2002. Involvement of GABA and cholinergic receptors in the nucleus accumbens on feedback control of somatodendritic dopamine release in the ventral tegmental area. J Neurochem 80: 646-654.

Rossato JI, Bevilaqua LR, Izquierdo I, Medina JH, Cammarota M. 2009. Dopamine controls persistence of long-term memory storage. Science 325: $1017-1020$. 
Schmidt HD, Famous KR, Pierce RC. 2009. The limbic circuitry underlying cocaine seeking encompasses the PPTg/LDT. Eur J Neurosci 30: $1358-1369$.

Schultz W. 1998. Predictive reward signal of dopamine neurons. J Neurophysiol 80: 1-27.

Sugimoto T, Hattori T. 1984. Direct projections from the globus pallidus to the paraventricular nucleus of the thalamus in the rat. Brain Res 323: 188-192.

Wallace TL, Porter RH. 2011. Targeting the nicotinic $\alpha 7$ acetylcholine receptor to enhance cognition in disease. Biochem Pharmacol 82: 891-903.

Woodruff-Pak DS, Lehr MA, Li JG, Liu-Chen LY. 2010. Young and older good learners have higher levels of brain nicotinic receptor binding. Neurobiol Aging 31: 1032-1043.
Wooltorton JR, Pidoplichko VI, Broide RS, Dani JA. 2003. Differential desensitization and distribution of nicotinic acetylcholine receptor subtypes in midbrain dopamine areas. J Neurosci 23: 3176-3185.

Yang K, Hu J, Lucero L, Liu Q, Zheng C, Zhen X, Jin G, Lukas RJ, Wu J. 2009. Distinctive nicotinic acetylcholine receptor functional phenotypes of rat ventral tegmental area dopaminergic neurons. J Physiol 587: 345-361.

Zhao-Shea R, Liu L, Soll LG, Improgo MR, Meyers EE, McIntosh JM, Grady SR, Marks MJ, Gardner PD, Tapper AR. 2011. Nicotine-mediated activation of dopaminergic neurons in distinct regions of the ventral tegmental area. Neuropsychopharmacology 36: 1021-1032.

Received December 3, 2012; accepted in revised form January 7, 2013. 


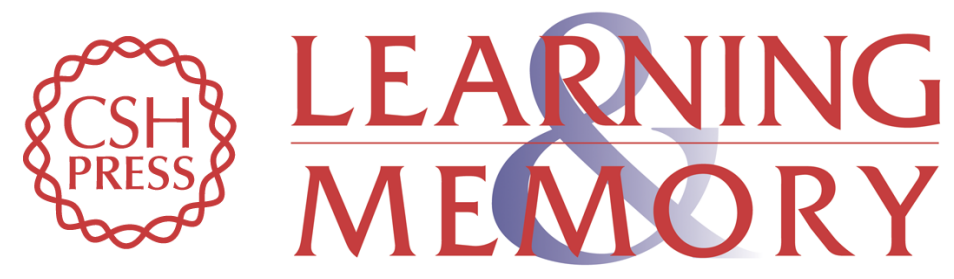

\section{Nicotine modulates the long-lasting storage of fear memory}

Ramón H. Lima, Andressa Radiske, Cristiano A. Köhler, et al.

Learn. Mem. 2013, 20:

Access the most recent version at doi:10.1101//m.029900.112

References This article cites 45 articles, 13 of which can be accessed free at: http://learnmem.cshlp.org/content/20/3/120.full.html\#ref-list-1

License

Email Alerting Receive free email alerts when new articles cite this article - sign up in the box at the Service top right corner of the article or click here. 